\title{
Isolation Frequency Switchable MIMO Antenna for PCS, WIMAX and WLAN Application
}

\author{
Adamu Halilu Jabire ${ }^{1 *}$, Anas Abdu ${ }^{1}$, Sani Saminu², Abubakar M. Sadiq ${ }^{3}$ and Mohammed J. Adamu ${ }^{3}$ \\ ${ }^{1}$ School of Electronics and Information Engineering, Hebei University of Technology P.R. China. \\ ${ }^{2}$ School of Electrical Engineering, Hebei University of Technology, P. R. China. \\ ${ }^{3}$ School of Microelectronics, Tianjin University, Tianjin 30072 P.R. China.
}

*Corresponding author: adamu.jabire@ @tsuniversity.edu.ng, Tel: +8615510965699, +2348036570803

\begin{abstract}
In this study, a lumped component based frequency reconfigurable multiple-input-multiple-output (MIMO) receiving wire design is presented. The proposed antenna is composed of a planar structure in form of F-shaped together with a slotted and defected ground structure for bandwidth and isolation enhancement. The MIMO antenna operates in six frequencies upon the state of the four lumped element switches. The proposed receiving wire design exhibits a multiband frequency reconfigurable characteristics from $1-7 \mathrm{GHz}$ with isolation of more than $14 \mathrm{~dB}$ for the whole band, with efficiency of about $75 \%$. The MIMO antenna's behavior in terms of ratio of square root of the sum of power reflected wave to the incident wave (TARC), ECC and CCL are all within the acceptable limits. The design is suitable for personal communication system (PCS), WIMAX and WLAN wireless applications.
\end{abstract}

Keywords: MIMO, Frequency reconfigurable, Lumped elements, Mutual coupling.

Article History: received 12 October 2019; accepted 5 December 2019; published 18 December 2019.

(C) 2019 Penerbit UTM Press. All rights reserved

\section{INTRODUCTION}

The demand for multiple/wideband operating frequencies in wireless communication framework is increasing these days. With these, frequency reconfigurable MIMO antennas have gained a remarkable recognition due to their ability to adjust the operating frequency band based on spectrum availability [1]. Frequency reconfigurable antennas are better choice as they work over small band and reject the clamor from unused ones which upgrades the unwavering quality of the framework. Reconfigurable MIMO antennas proffer's a solution where by it can switch or tune the operating frequency to a desired band by using some techniques. We have several types of reconfigurable antennas such as radiation pattern reconfigurability [2], frequency [3] - [8], polarization [9] and bandwidth [10].

This study only focused on frequency tunable antennas. One of the challenges of the MIMO antenna is the electromagnetic interaction among the array elements termed as mutual coupling [11]. Designing the MIMO antennas requires a lot of consideration for minimizing the mutual coupling effect because, the effect severely degrades how the MIMO antenna performs. Several designs of frequency reconfigurable MIMO antennas have been proposed in [12] - [19] of which most of the designs are reconfigurable antennas. A design of reconfigurable metal edge MIMO handset reception apparatus with circulated bolstering is introduced in [12]. The antenna depends on switches and the antenna cluster idea. Another design of reconfigurable antenna based on reconfigurable microstrip feedline is presented in [13], in which varactor diodes are integrated within the feedline to achieve frequency reconfigurability. A design presented in [14] used RF switch for frequency tuning capability. The RF switch is used in the ground short pin of the dual port antenna for impedance switching. A pin diode is used in [15] to achieve operating band reconfigurability. The antenna framework gives switchable band gap capability for WIMAX (3.2 $3.8 \mathrm{GHz})$ band. The used of microelectromechanical (MEMS) switch is presented in [16] - [17]. The reception apparatus is proficient in beam steering on the XZ-plane upon MEMS put on the antenna feeding line. A pattern and frequency reconfigurable antenna is presented in [18]. The antenna used a single feed line with the help of diodes. The radiation pattern reconfiguration is achieved by rotating the patch. A lumped element switch is employed in [19] and [20]. The lumped components are utilized in the simulation environment to accomplish tunable capacitance which is responsible for frequency reconfigurability. However, the methodology used in majority of the above mentioned papers have some disadvantages for the fact that they are not easily modeled and are not conveniently integrated within the structure.

In this paper, a $2 \times 2$ isolation frequency reconfigurable MIMO antenna is designed on the FR4 substrate with thickness of $1.6 \mathrm{~mm}$. The MIMO antenna transmits in six different frequency bands which include personal communication system (PCS), WIMAX and WLAN band. The lumped components are employed as switch within the radiator to accomplish the frequency reconfigurability. The value of the $R$ used which configure the state of the switch is $R=1 \Omega$ (switch ON) and $R=1 \mathrm{k} \Omega$ (switch OFF). A space of $1 \mathrm{~mm}$ is saved for the integration of each switch. The rest of the manuscript 
is sorted out as follows: section 2 is the antenna geometry and design, while section 3 discussed the simulation results, section 4 presents the MIMO system metrics and section 5 finishes up the study.

\section{ANTENNA DESIGN}

\subsection{Antenna Geometry}

The proposed frequency reconfigurable MIMO antenna is derived from two planar rectangular monopole antenna fed by $50 \Omega$ microstrip line. The step-by step design procedure is shown in figure 1 . The detailed geometry of the top and bottom view are shown in figure $2 \mathrm{~A}$ and $2 \mathrm{~B}$, respectively. The optimum parameters of the proposed antenna are given in table 1 . The $2 \times 2$ reception apparatus is designed on FR4 substrate with a permittivity of 4.3, $\tan \delta=0.025$, and $1.6 \mathrm{~mm}$ thick. The electromagnetic design and simulation of this work are performed in the commercial full wave simulator CST 2017 version.

Step 1

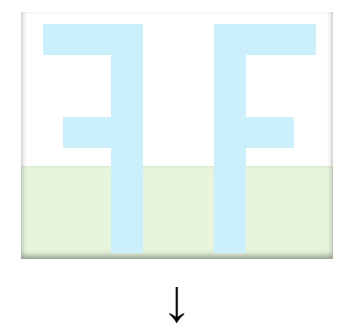

Step 2
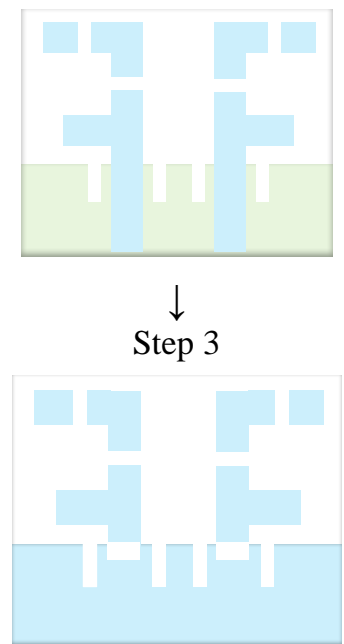

Figure 1. The design evolution of the $2 \times 2 \mathrm{MIMO}$ antenna

\subsection{Parametric Analysis of the Design}

The design evolution is presented using three different steps as mentioned above. Besides, the reflection coefficient plots for all the intermediate steps involved in design process are provided in figure 3 for identifying the effect or influence of each design step on the impedance bandwidth. The step 1 , as shown in figure 1 is a $2 \times 2$ monopole with a partial ground plane having a length of $\mathrm{G}_{\mathrm{L}}=16 \mathrm{~mm}$. In the second step, slits are added in the ground plane which, alters the current distributions in the plane. The surface current of defective ground structure in step 2 alter the input impedance of the MIMO antenna and improve the impedance bandwidth. Four different slits are also added on the radiating elements which helps in improving the impedance bandwidth and also serve as a place where our switches can be integrated for reconfigurability. In the final design step, that is, step 3 two notches are employed in the ground plane. The two notches introduced in step 3 alter the surface currents in the ground plane and contributes in impedance matching around $-18 \mathrm{~dB}$ as shown in figure 3 .

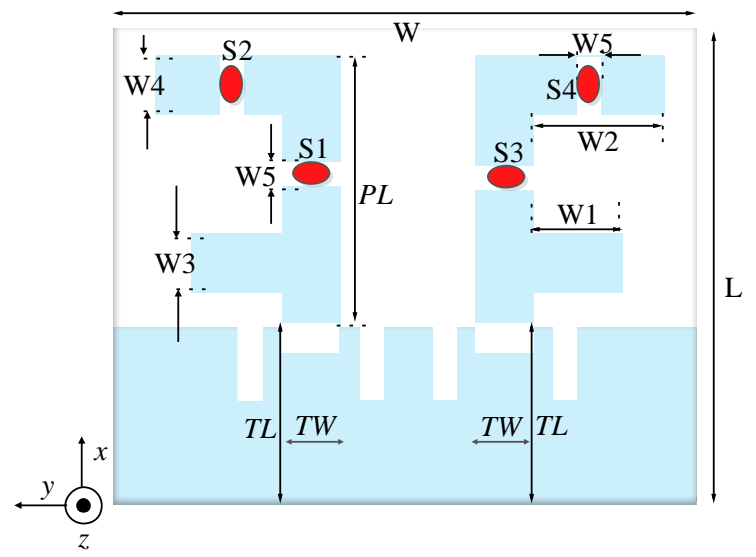

(A)

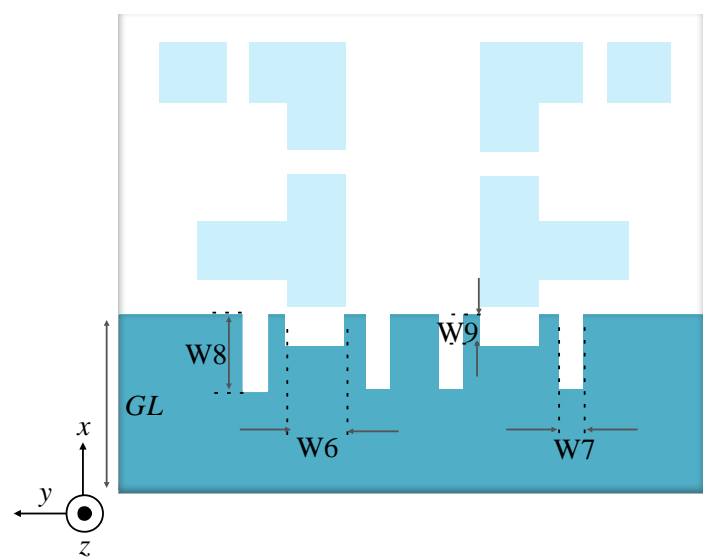

(B)

Figure 2. 2x2 MIMO antenna geometry: A, top layer, B, ground plane

Table 1. Optimized antenna parameters

\begin{tabular}{|c|c|c|c|}
\hline Parameter & Size (mm) & Parameter & Size (mm) \\
\hline $\mathrm{L}$ & 40 & $\mathrm{~W}_{2}$ & 9 \\
\hline $\mathrm{W}$ & 50 & $\mathrm{~W}_{3}$ & 2 \\
\hline $\mathrm{G}_{\mathrm{L}}$ & 16 & $\mathrm{~W}_{4}$ & 3 \\
\hline $\mathrm{P}_{\mathrm{L}}$ & 23 & $\mathrm{~W}_{5}$ & 1 \\
\hline $\mathrm{T}_{\mathrm{L}}$ & 16 & $\mathrm{~W}_{6}$ & 3 \\
\hline $\mathrm{T}_{\mathrm{W}}$ & 3 & $\mathrm{~W}_{7}$ & 2 \\
\hline $\mathrm{H}$ & 1.6 & $\mathrm{~W}_{8}$ & 5 \\
\hline $\mathrm{W}_{1}$ & 2.81 & $\mathrm{~W}_{9}$ & 0.4 \\
\hline
\end{tabular}

\section{RESULTS AND DISCUSSION}

\subsection{Reflection Coefficient of the MIMO Antenna}

Four element switches is used for four possible modes of procedure which is shown in table 2. Lumped element switch is preferred because it is easily configured in CST as a resistor of $1 \Omega$ and $1 \mathrm{k} \Omega$ to control the switch in ON and OFF mode respectively. The MIMO antenna operates 
in mode 1 when the switch is set in the ON state. In this mode the MIMO antenna gives two frequencies of $1.7 \mathrm{GHz}$ and $5.1 \mathrm{GHz}$. The two frequencies are used for PCS and WLAN application. Figure 4 shows the simulated $S_{11}$ for the $O N$ state. Figure 5 remain the isolation coefficient $\left(\mathrm{S}_{21}\right)$ of the MIMO antenna. Mode 2 is the OFF state that is, when the four switches are off, $3.35 \mathrm{GHz}$ was realized as shown in figure 6 , while figure 7 is the $S_{21}$ of the MIMO antenna when the switch is off. Mode 3 is when $S_{1}$ is ON, $S_{2}$ is OFF, $S_{3}$ is ON and $S_{4}$ is $\mathrm{OFF}, 5.6 \mathrm{GHz}$ is attained as shown in figure 8 . The $S_{21}$ of the mode is presented in figure 9 . In mode 4 which is the last mode $S_{1}$ is OFF, $S_{2}$ is ON, $S_{3}$ is OFF and $S_{4}$ is $O N$, two dual frequencies are realized at $3.3 \mathrm{GHz}$ and $5.28 \mathrm{GHz}$ as depicted in figure 10 . The $S_{21}$ is shown in figure 11 . In all the four modes more than $14 \mathrm{~dB}$ isolation is attained.

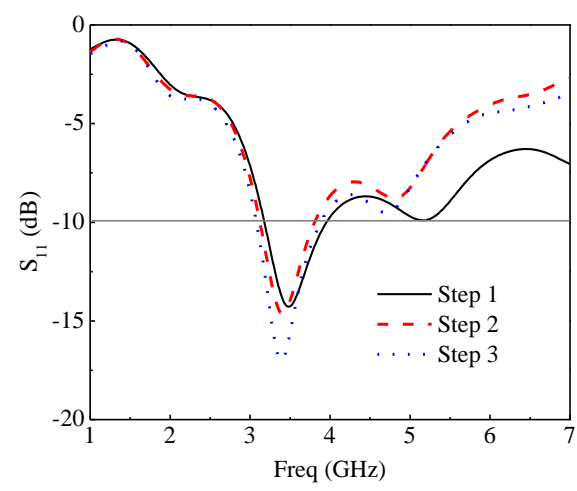

Figure 3. $\mathrm{S}_{11}$ plots for each design step

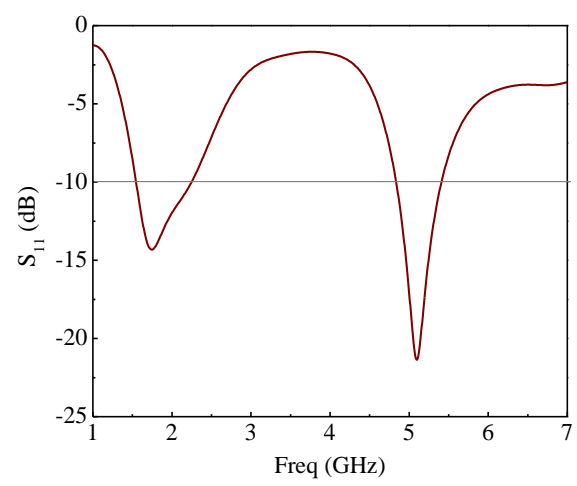

Figure 4. Simulated $\mathrm{S}_{11}$ for mode 1

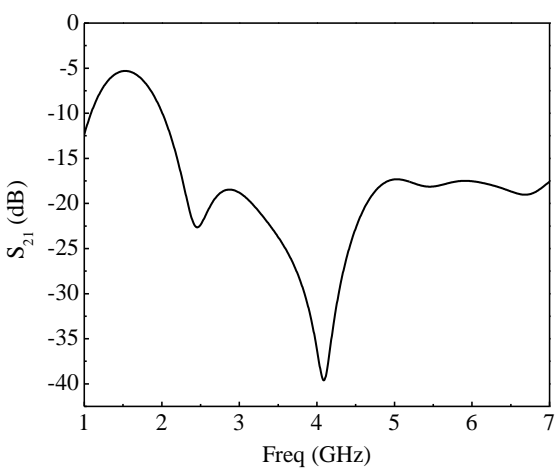

Figure 5. Simulated $\mathrm{S}_{21}$ for mode 1

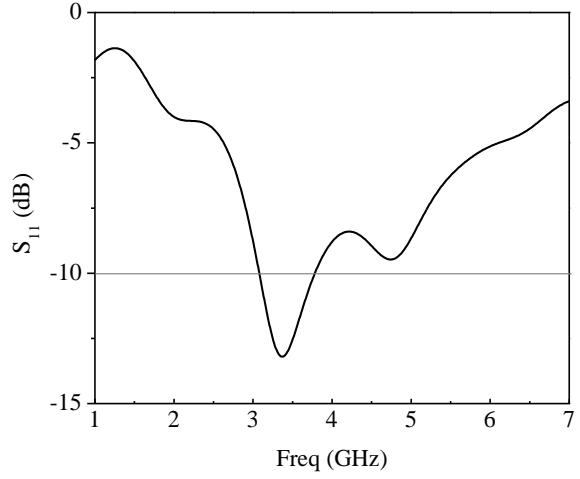

Figure 6. Simulated $S_{11}$ for mode 2

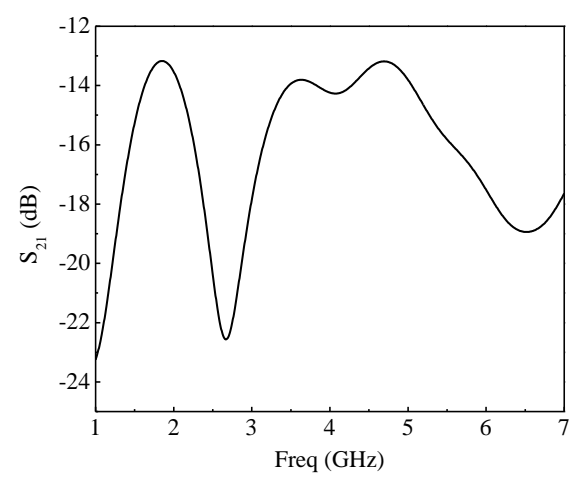

Figure 7. Simulated $S_{21}$ for mode 2

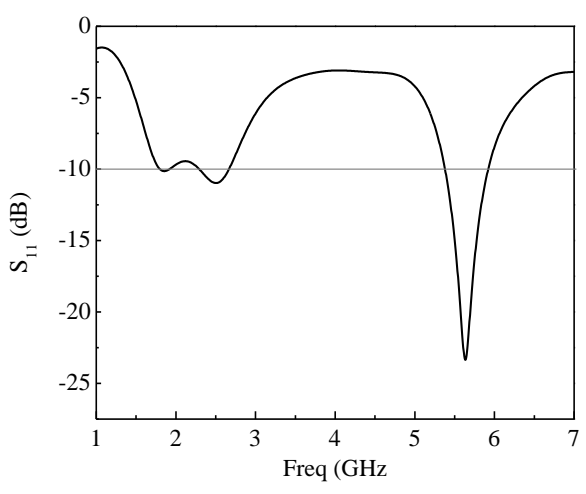

Figure 8. Simulated $S_{11}$ for mode 3

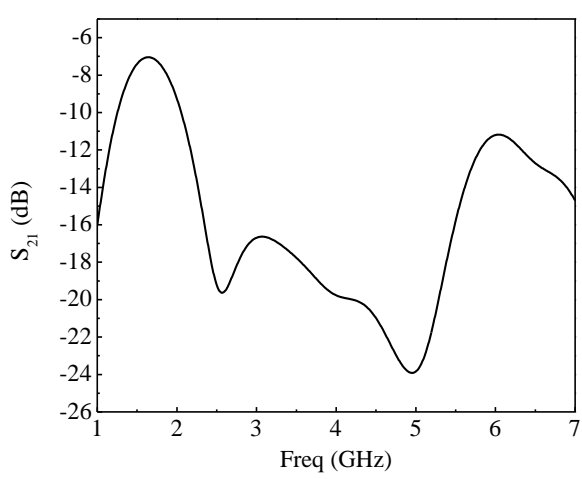

Figure 9. Simulated $S_{21}$ for mode 3 


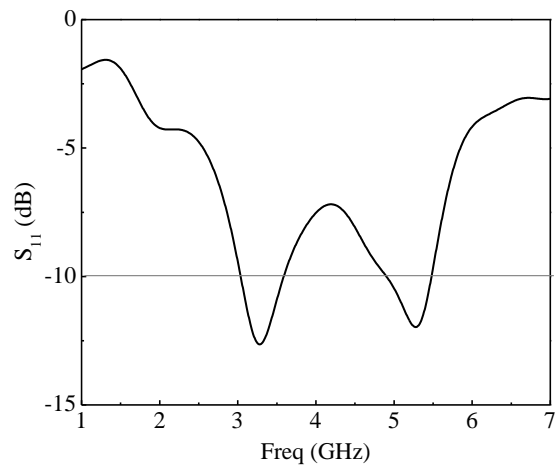

Figure 10. Simulated $S_{11}$ for mode 4

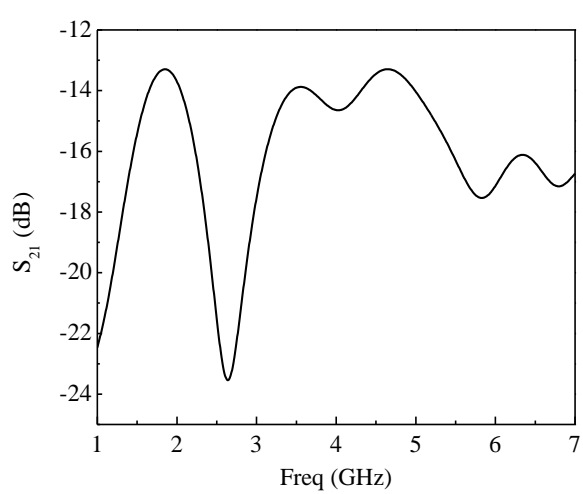

Figure 11. Simulated $S_{21}$ for mode 4

Table 2. Frequency mode of the proposed antenna

\begin{tabular}{|l|l|l|l|l|l|}
\hline Modes & $\mathbf{S}_{\mathbf{1}}$ & $\mathbf{S}_{\mathbf{2}}$ & $\mathbf{S}_{\mathbf{3}}$ & $\mathbf{S}_{\mathbf{4}}$ & Frequency \\
\hline Mode 1 & ON & ON & ON & ON & $1.7 \mathrm{GHz}, 5.1 \mathrm{GHz}$ \\
\hline Mode 2 & OFF & OFF & OFF & OFF & $3.35 \mathrm{GHz}$ \\
\hline Mode 3 & ON & OFF & ON & OFF & $5.6 \mathrm{GHz}$ \\
\hline Mode 4 & OFF & ON & OFF & ON & $3.3 \mathrm{GHz}, 5.28 \mathrm{GHz}$ \\
\hline
\end{tabular}

\subsection{Radiation Pattern of the MIMO antenna}

Radiation pattern of the proposed 2x2 MIMO antenna are simulated using CST studio version 2017. The plot at $1.7 \mathrm{GHz}, 3.3 \mathrm{GHz}$ and $3.35 \mathrm{GHz}$ is shown in figure 12 , while figure 13 is the pattern plot at $5.1 \mathrm{GHz}, 5.28 \mathrm{GHz}$ and 5.6GHz.. As can be seen from all the plots the MIMO antenna has approximately omnidirectional radiation pattern

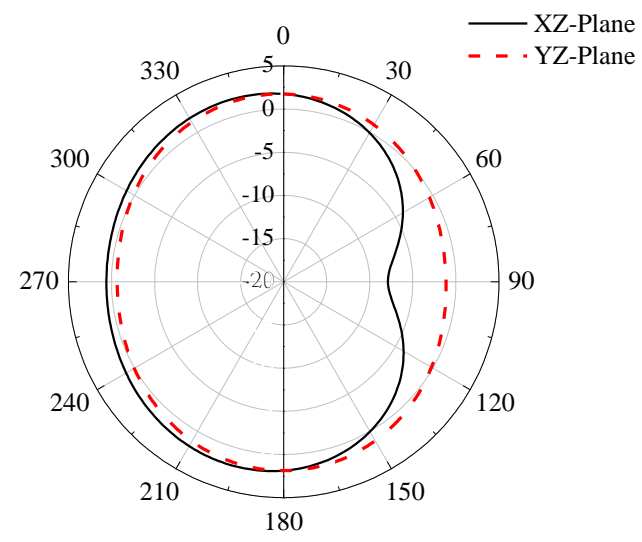

(a)

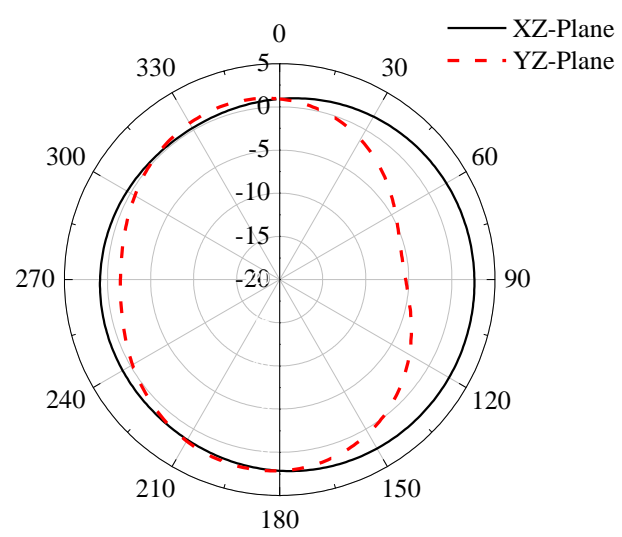

(b)

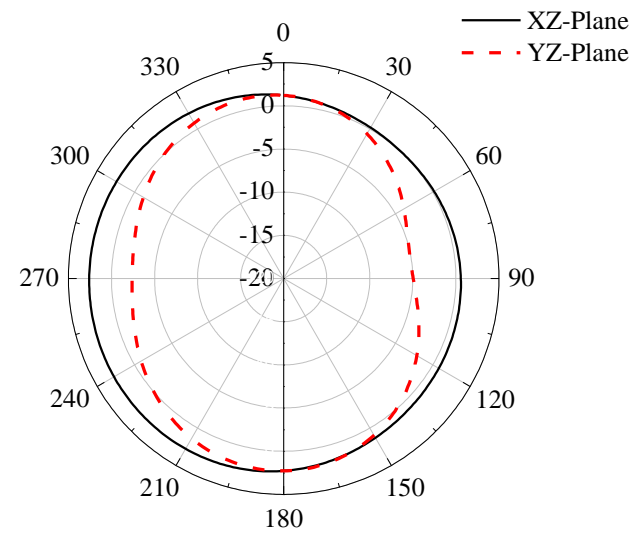

(c)

Figure 12. Radiation pattern at (a) $1.7 \mathrm{GHz}$, (b) $3.3 \mathrm{GHz}$, and (c) $3.35 \mathrm{GHz}$ 


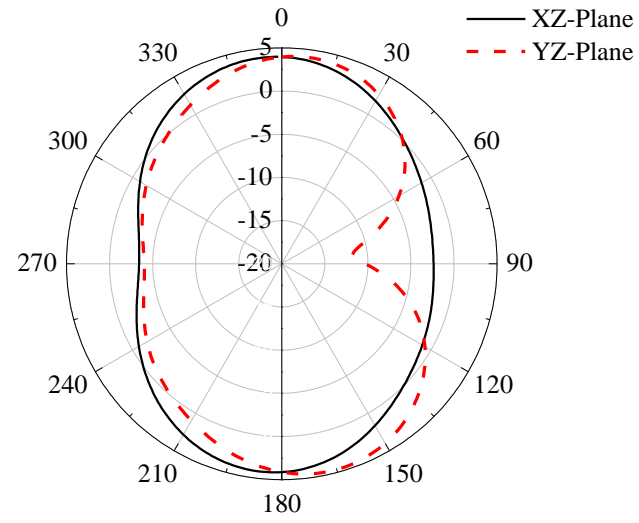

(a)

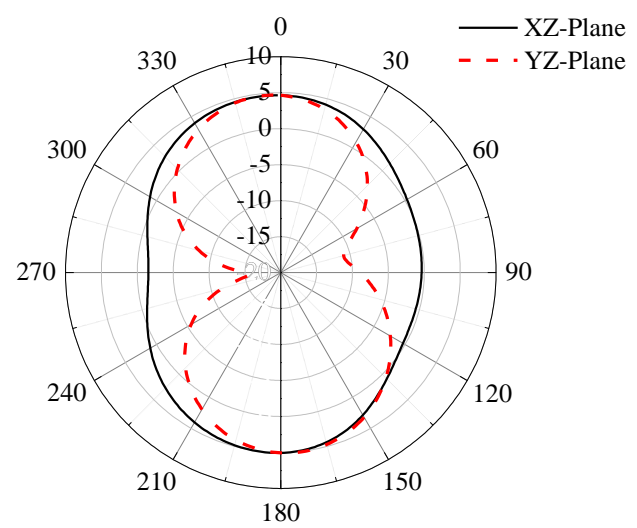

(b)

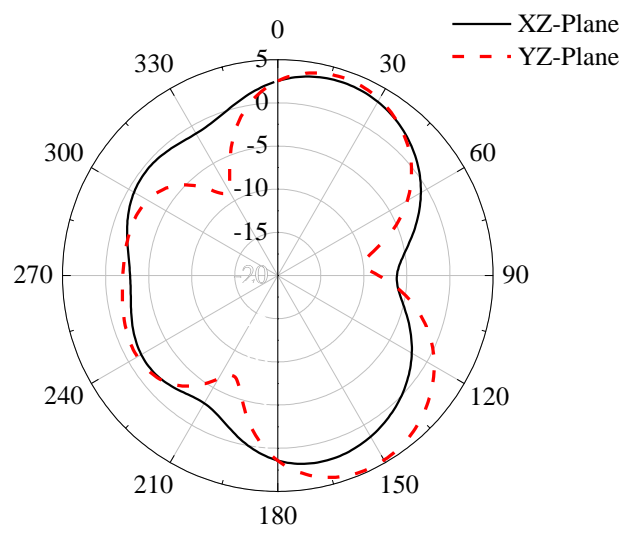

(c)

Figure 13. Radiation pattern at (a) $5.1 \mathrm{GHz}$, (b) $5.28 \mathrm{GHz}$ and (c) $5.6 \mathrm{GHz}$

\section{MIMO SYSTEM METRICS}

The important parameters which serves as the determinant factors for the coupling coefficient between the MIMO antenna elements is called the envelope correlation coefficient. Virtually ECC factor must be less than 0.5 and is usually computed using the $\mathrm{S}$-parameter given in equation 1 . The ECC plot is pictured in figure 14 which is lower than 0.001 over the frequency of interest. Another important parameter for the implementation of MIMO antenna is diversity gain, it is obtained when two or more antennas are used, which is calculated using equation 2. Diversity gain plot for the proposed MIMO antenna is presented in figure 15 . It is clearly seen that the value is almost 10dB. A good diversity gain performance is clearly exhibited by the antenna.

$$
\begin{gathered}
E C C=\frac{\left|S_{11}^{\bullet} S_{12}+S_{21}^{\bullet} S_{22}\right|}{\left(1-\left|S_{11}^{2}\right|-\left|S_{21}^{2}\right|\right)\left(1-\left|S_{22}^{2}\right|-\left|S_{12}^{2}\right|\right)} \\
D G=10 \sqrt{1-E C C^{2}}
\end{gathered}
$$

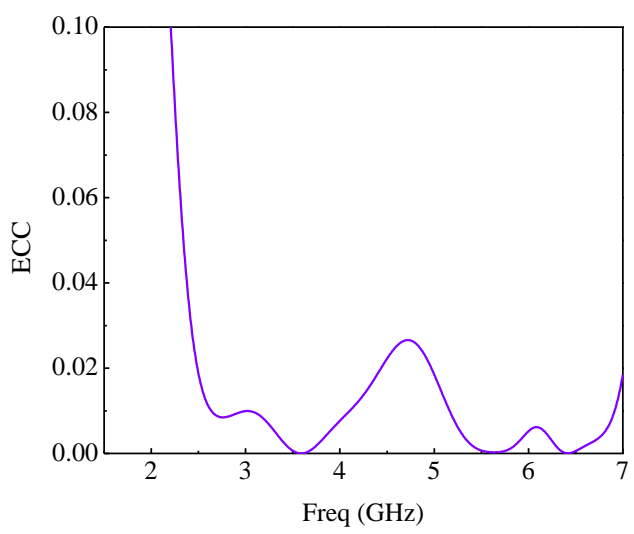

Figure 14. ECC of MIMO antenna system

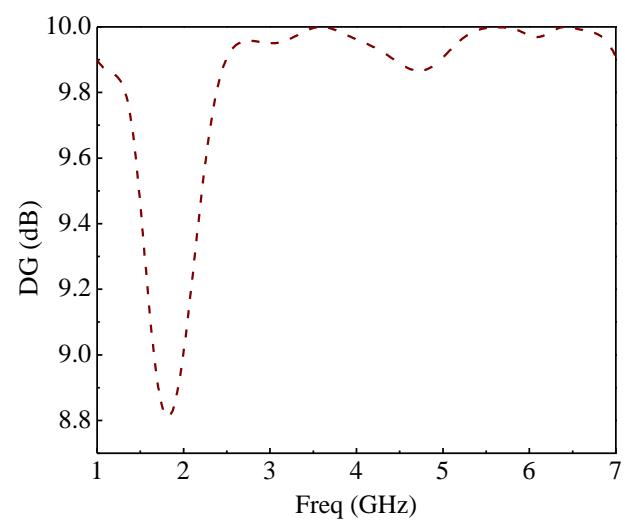

Figure 15. Diversity gain of the MIMO antenna

Total active reflection coefficient (TARC) is one of the coupling coefficient between the MIMO antenna elements for a two-port MIMO antenna. TARC can be computed using equation 3 [21]. The TARC is dependent on scattering parameters from port 1 to port 2 and vice versa. Practically, the value of TARC must be lower than OdB. Figure 16 is the TARC plot using Matlab 2018 and origin 8 for the plot. $\theta$ is considered as variable angle which is related to phase of excitation signal. TARC was considered from 0 degrees to 180 degrees with an interval of $30^{\circ}$. The plot reveals that $0 \leq r_{a}^{t} \leq 1$.

$$
T A R C=\frac{\sqrt{\left|S_{11}+S_{12} e^{j \theta}\right|^{2}+\left|S_{22}+S_{21} e^{j \theta}\right|^{2}}}{\sqrt{2}}
$$

Increasing the number of antennas will lead to an increase in the channel capacity of the MIMO system, some losses will be included in the channel due to the presence of correlation. Channel capacity loss is one of the important feature that describes data rate that can be supported in a particular channel. CCL can be calculated from simulated S-parameters using the equation 4 below. The CCL is 
presented in figure 17 in which, the plot shows that the CCL are less than 0.2 over the frequency of interest.

$$
C C L=-\log _{2} \operatorname{det}\left(\psi^{R}\right)
$$

Figure 18 is the peak gain over the frequency and the efficiency of the MIMO antenna, more than $70 \%$ of efficiency is attained by the MIMO antenna.

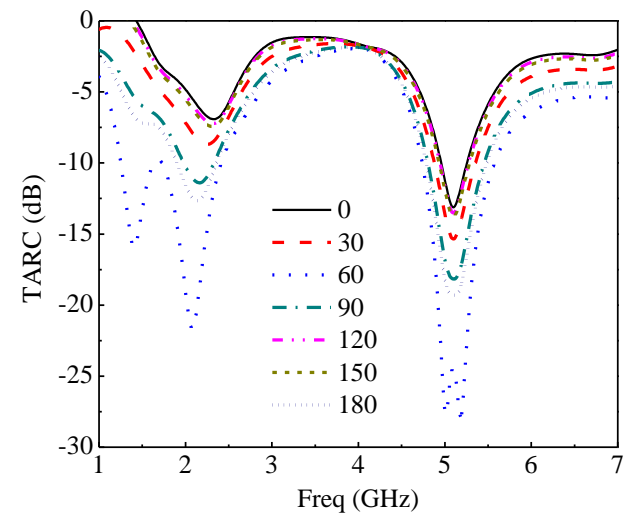

Figure 16. TARC of the $2 \times 2$ MIMO antenna system

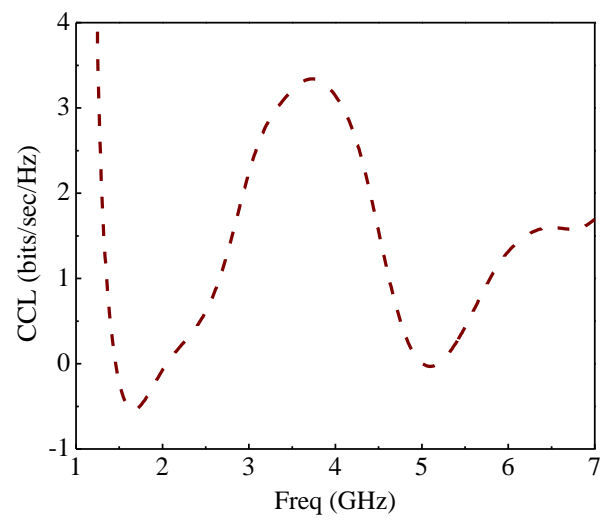

Figure 17. CCL of the 2x2 MIMO antenna system

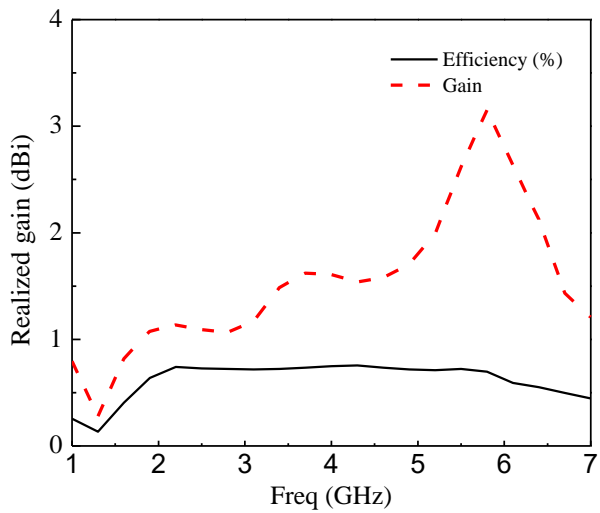

Figure 18. Realized gain and efficiency of the MIMO antenna

\section{CONCLUSION}

This work presents a frequency reconfigurable MIMO antenna for PCS, WIMAX and WLAN application. Numerical outcomes are given to exhibit the proposed model. With an efficiency of more than $70 \%$ the proposed antenna provides low polarization diversity aims at attaining the low mutual coupling which provides low latency, increased user rate, reduce cost and energy and finally increase the capacity in terms of traffic and connections.

\section{ACKNOWLEDGMENT}

The authors will like to thank the school of electronics and information engineering, Hebei University of Technology P.R China for their kind support.

\section{REFERENCES}

[1] Y. Insang, M. F. Imani, S. Timothy et al, "Enhancing capacity of spatial multiplexing systems using reconfigurable cavity-backed metasurface antennas in clustered MIMO channels," IEEE Trans. Communications, vol. 67(2), pp. 10701084, 2019.

[2] L. Marantis, D. Rongas, A. Paraskevo poulas et al, "Pattern reconfigurable ESPAR antenna for vehicle to vehicle communications," IET Microw. Antennas and Propagation, vol. 12(3), pp. 280-286, 2018.

[3] M. Rohit and S. Dwari "Compact planar reconfigurable UWB-MIMO antenna with ondemand worldwide interoperability for microwave access/wireless local area network rejection," IET Microw Antennas Propagation, vol. 13(10), pp. 1684-1689, 2019.

[4] A. Mansoul and M. L. Seddik, "Multiband reconfigurable bowtie slot antenna using switchable slot extensions for WIFI, WIMAX and WLAN applications," Microw and Opt Tech. Lett, vol. 60 no.2, pp. 413-418, 2018.

[5] A. Tanweer, M. Khaleeq Mohammed and R. C. Biradar, "A multiband reconfigurable slot antenna for wireless applications,". Int. J. Elect and Commun, vol. 84, pp. 273-280, 2018.

[6] A. Tanweer, F. Nikhat and R. C. Biradar, "A miniaturized multiband reconfigurable fractal slot antenna for GPS/GNSS/Bloetooth/EIMAX/X-Band applications," Int. J. Elect and Commun, vol. 94 pp. 234-243, 2018.

[7] G. Srivastava, A. Mohan and A. Chakraborty, "Compact reconfigurable UWB slot antenna for cognitive radio applications," IEEE Antennas Wirel. Propag. Lett, vol. 16, pp.1139-1142, 2017.

[8] S. Chagharvand, M. Rijal Hamid, M. Ramlee Kamarudin et al, "Wide to narrowband reconfigurable vivaldi antenna using switched feed technique," Telecomm System, vol. 63, pp. 711-717, 2016.

[9] Ke Li, and Yan Shi "A characteristic mode based polarization reconfigurable antenna and its array," IEEE Access, vol. 6, pp. 64587-64595, 2018.

[10] A. Mansoul, F. Ghanem, M. R. Hamid et al, "Bandwidth reconfigurable antenna with a fixed lower and a variable upper limit," IET Microw Antennas Propagation, vol. 10(15), pp. 1725-1733, 2016.

[11] A. Ghaffar, X. Jun LiS. Boon-Chong,’Dual frequency band and polarization reconfigurable antenna for mobile devices," 2017 IEEE Int. Conference on Communication Technology (ICCT), Chengdu, China, 2017, pp. 696-700. 
[12] A. H. Jabire, H-X Zheng, A. Abdu et al, "Characteristic mode analysis and design of wide band MIMO antenna consisting of metamaterial unit cell," Electronics, vol. 8(1), pp.1-14, 2019.

[13] L. Rasmiu, J-M Hannula, L. Anu et al, "Switch reconfigurable metal rim MIMO handset antenna with distributed feeding," IEEE Access, vol. 7, pp. 48971-48981, 2019.

[14] X. Zhao and S. Riaz, "A dual band frequency reconfigurable MIMO patch slot antenna based on reconfigurable mixrostrip feedline. IEEE Access, vol. 6, pp. 4150-41457, 2018.

[15] W-W Lee and B-C Jang "A tunable MIMO antenna with dual port structure for mobile phones," IEEE Access, vol. 7, pp. 34113-34120, 2019.

[16] A. Quddus, R. Saleem, M. F Shafique et al, "Compact electronically reconfigurable WIMAX band-notched ultrawideband MIMO antenna," Radio Engineering vol. 27(4), pp. 998-1005, 2018
[17] H. Lago, Z. Zakaria, M. F. Jimlos et al, "A wide band reconfigurable folded planar dipole using MEMS and hybrid polymeric substrates," Int. J. Elect and Commun, vol. 99, pp. 347-353, 2019.

[18] Khan MS, A. Iftikhar, A-D Capo-bianco et al, "Pattern and frequency reconfiguration of patch antenna using pin diodes,"Microw Opt. Technol Letters, vol. 59, pp.2180-2185, 2017

[19] A. Shah, S. Hayat, A. Basir, et al, "“Design and analysis of a hexa-band frequency reconfigurable antenna for wireless application," Int. J. Elect and Commun, vol. 98, pp. 80-88, 2019.

[20] S. Ullah, S. Ahmad, B. A. Khan et al, "A multiband switchable antenna for WIFI, 3G advanced WIMAX and WLAN wireless application," Int. J. Microw Wirel Tech, vol. 10(8), pp. 991-997, 2018.

[21] Elwi Taha A. "A miniaturized folded antenna array for MIMO applications," Wirel Personal Commun, vol. 98(2), pp. 1871-1883, 2018. 